\title{
LA HISTORIA RECIENTE: ARGENTINA REFLEXIONES SOBRE “EL PROCESO DE REORGANIZACIÓN NACIONAL" (1976-1983)
}

\author{
Mabel Muñoz Matiu \\ Universidad Ricardo Palma \\ mabu@yahoo.es
}

\section{RESUMEN}

La historia reciente es una historia cuya mirada se dirige más a las rupturas radicales que a las continuidades, es una historia que exige al historiador nuevos conceptos, nuevas técnicas y herramientas epistemológicas. Es una historia que se enfrenta a problemas éticos, morales y políticos vigentes al momento de la investigación.

\section{PALABRAS CLAVE}

Historia / Argentina / Proceso / Reorganización Nacional / Violencia.

\begin{abstract}
Recent history is a story whose gaze is directed more to radical ruptures that continuities, is a story that requires the historian new concepts, new techniques and epistemological tools. It is a story that confronts ethical, moral and political problems existing at the time of the investigation.
\end{abstract}

\section{KEYWORDS}

History / Argentina / Process / National Reorganization / Violence. 


\section{UNA HISTORIA EN CONSTRUCCIÓN}

La historia reciente exige más que nunca las relaciones interdisciplinarias, porque necesita los aportes de la Sociología, la Antropología, las Ciencia Políticas y la Economía, pero también necesita un dialogo constante con la gente del diario vivir que actúan en diferentes campos ya sean políticos, gremiales, culturales, religiosos y ellos son quienes están inmersos en un compromiso que despierta pasiones, emociones y es en este campo donde es difícil mantener la objetividad y la distancia clásica que se exige en estos trabajos. El investigador está expuesto a mantener un dialogo con los protagonistas de la experiencia inmediata, con los testigos de acontecimientos vividos en un pasado no lejano. El historiador del pasado cercano se encuentra inmerso en una realidad en la que es testigo y juez y del cual se espera que evite los errores del común de la gente, se le exige que en lo posible sea objetivo en situación tan especial donde el historiador no puede ignorar su rol político y cívico. Donde debe plantearse y discutir una multitud de problemas que no han sido suficientemente estudiados ni discutidos y sin embargo tiene que asumirse como un precursor en el planteamiento de dichos problemas, en temas y discusiones abiertas que serán retomados $\mathrm{y}$ vueltos a tratar en profundidad por otros investigadores que quieran y puedan hacerlo con mayor rigor. La historia reciente requiere por lo tanto de un trabajo conjunto y ordenado entre investigadores de profesiones diversas porque a través de los diferentes enfoques se irá construyendo el objeto de estudio.

La historia reciente trata de estudiar un pasado en donde se mezcla lo público con lo íntimo, lo privado, las experiencias propias del sujeto que realiza el estudio en tanto le pueden llegar los ecos de los sucesos acaecidos no hace mucho tiempo. Un pasado que se alimenta de vivencias y recuerdos no tan ajenos, vividos y narrados por los mayores, es un pasado que se actualiza y se proyecta al futuro.

Al estudio de la historia reciente se lo conoce con otras denominaciones: Historia del Presente, Historia Inmediata, Historia Actual, Historia Vivida, Historia de Nuestros Tiempos y entonces cabe preguntarse ¿Cuál es el pasado reciente? ¿Qué periodo abarca? ¿Cuándo este pasado deja de ser reciente?

Pareciera que no es la cronología la más adecuada para ubicar la historia reciente, sino que tiene que ver más con las diversas formas de 
coetaneidad entre pasado y presente; la existencia aun de protagonistas y personajes en condiciones de brindar sus testimonios al historiador supone la existencia de una memoria compartida por la sociedad y el historiador. En este caso es difícil de establecer fechas de inicio y de cierre. Es una historia que se desarrolla entre actores y protagonistas que brindan sus testimonios al historiador donde conviven la memoria social y la contemporaneidad del historiador del pasado de que se ocupa.

La historia reciente enfoca su estudio en temas y problemas vinculados a procesos sociales de profundas rupturas, de graves conflictos tanto a nivel individual como colectivo, aunque vale aclarar que esto no es siempre así, pero sí lo es cuando se refiere a la historia reciente de los países de América del Sur, nos referimos a la década del 1970 y este es el caso de la Argentina cuando se estudia el "Proceso de Reorganización Nacional" que abarcó el periodo de 1976 a 1983.

La historia reciente exige trabajar la relación de la historia con la memoria, con el testimonio y con la expectativa social acerca del pasado cercano (Franco y Levin, p. 40).

Para Ricour historia y memoria son dos formas de presentación del pasado gobernadas por regímenes diferentes, pero que guardan una estrecha relación, mientras la historia busca la verdad, la memoria pretende llegar a la fidelidad. La memoria es útil para la historia siempre y cuando se tenga en cuenta una serie de métodos porque los individuos no guardan datos históricos de manera pasiva, sino que en el recuerdo está presente la subjetividad del que hace memoria y se produce deformaciones, olvidos, pero todo esto le sirve al historiador, en ciertas ocasiones, más que la reconstrucción de hechos del pasado porque puede llegar a estudiar subjetividades y experiencias que de lo contrario le sería muy difícil de conocer. El historiador debe tener en cuenta tanto los silencios y olvidos individuales como los colectivos y comprender porque algunos olvidan y otros no.

Las memorias de las dictaduras militares acaecidas en el Cono Sur durante la década de 1970 al 80 se convirtieron en importante objeto de estudio y según Jelin estas son memorias en conflicto. Vale entonces preguntarse ¿Cuál es la relación que debe guardar el historiador con el testigo? ¿En qué medida el historiador puede poner una distancia con su objeto? ¿Cómo poder llegar a una historiografía crítica? Todas estas 
preguntas surgen porque el investigador está estudiando un pasado cercano del cual es contemporáneo y está incluido, donde vive una situación de intercambio entre él y el sujeto interrogado, y puede ser que pertenezcan a diferentes clases sociales y también puede existir diferencias de género y de generación, diferencias que crean tensiones y lógicas distintas en la situación, en la investigación. Para superar estas dificultades que se le presentan, el historiador debe actuar con gran rigor en la selección de las fuentes, las que a veces son escasas, otras veces muy abundantes y en ciertas oportunidades no confiables, sin olvidar una dificultad de esta historia al tratarse de un proceso no acabado, no cerrado. El trabajo en la historia reciente se centra en la necesidad, como ya se ha mencionado, de un rigor de la selección de las fuentes, en la contrastación y verificación, en aplicar un trabajo interdisciplinario, en mantener una distinción consciente entre compromiso político o social y la tarea profesional y en la particular vinculación con los objetos de estudio (Soulet, pp. 66-76, 114-117).

Teniendo presente las características arriba mencionadas podemos enfocar el estudio de la historia reciente en la Argentina, estudio que ha provocado ciertas diferencias entre los investigadores en lo que se refiere a la cronología, lo cual ha planteado la diferencia de criterios porque para algunos historiadores esta se ubica después del proceso y en este caso se estudia la Argentina en democracia. Sin embargo son abundantes las investigaciones dedicadas al periodo 1976 a 1983; de acuerdo con este criterio lo sucedido durante el proceso corresponde a la historia reciente, no sólo porque pertenece a un tiempo no lejano, sino sobre todo por sus características que han sido ya mencionadas, es el estudio de una época de rupturas, de graves conflictos, de hechos de violencias, de terrorismo de Estado; es una investigación donde es muy difícil contar con archivos porque muchos fueron eliminados, las fuentes estatales o militares le son negados al investigador, están ocultas o han sido sacadas del país. Por ello es que el testimonio oral se convirtió en la figura esencial, y en esta situación se tiene que contar con los testigos y protagonistas directos de los acontecimientos estudiados y entonces no se puede ignorar el gran el problema que plantea este tipo de fuentes, porque el testimonio oral "expresa no sólo la percepción de un testigo, de una experiencia vivida, sino la mirada, los discursos y la expectativas de su sociedad en el momento en el que es formulado" (Wieviorka, p.13), por todo esto se plantea la cuestión de la utilización de las fuentes orales y de las técnicas de la historia oral. Y no hay que olvidar que aún hoy se está bajo cierta influencia de la historia positivista que le dio confiabilidad a las fuentes escritas por desconfiar de 
la subjetividad de las fuentes orales "sobre todo porque son coproducidas por el investigador mismo en la instancia de entrevista" (Franco y Levin, p. 53); sin embargo, se puede señalar, algo semejante sucede con las fuentes extraídas de un archivo por cuanto fueron seleccionadas e interpretadas por el historiador.

\section{LA ARGENTINA Y LOS CONFLICTOS EN EL SIGLO XX}

Estudiando la historia del siglo XX en la Argentina se observa que entre los años 1930 y 1976 se produjeron seis golpes de Estado, estos fueron los de 1930, 1943, 1955 y 1962, de característica distinta a los de 1966 y 1976, porque los cuatro primeros establecieron gobiernos de facto, que tenían como objetivo poner "orden en el país", en cambio los dos últimos se propusieron cambiar la estructura del estado y de la sociedad.

Cabe destacar que la década de 1970 se caracterizó por una fuerte movilización, producto de un agudo problema social, dando lugar a la organización armada con apoyo popular que contó con la participación de jóvenes universitarios, obreros y de algunos miembros de la iglesia católica.

Por un lado estaba la Juventud Peronista defensora del ex presidente Perón, quien se encontraba en el exilio desde el golpe que lo derrocó en 1955. Esta juventud se organizó como grupo guerrillero a través del movimiento Montonero y tuvo importante presencia a nivel popular.

De otro lado estaba la organización guerrillera denominada Ejercito Revolucionara del Pueblo (ERP) que desconfiaba del peronismo y que buscaba la liberación del pueblo latinoamericano y se alimentaba de las ideas trotskistas y tenía como gran figura inspiradora al Che Guevara.

Sin embargo en 1973 se realizaron las elecciones en la que obtuvo la victoria el peronismo, pero un peronismo sin Perón debido a que su candidatura fue vetada por los militares que gobernaron hasta esa fecha; no obstante Perón designó como candidato a Héctor Cámpora que asumió como presidente en mayo del año mencionado. En junio Perón logró después de casi 20 años de exilio regresar a la Argentina y se presentó en setiembre como candidato en nuevas elecciones y ganó con más del $60 \%$ de los votos. Cámpora fue dejado de lado por Perón, porque apoyaba a las organizaciones de izquierda. Una vez en la presidencia el líder trató de desalojar del partido a los grupos de izquierda que habían luchado 
por su regreso; ante esta actitud de Perón, los jóvenes de la izquierda le respondieron con críticas y protestas; esta situación de enfrentamiento y ruptura entre las diferentes corrientes del peronismo quedó al descubierto cuando Perón, el 1 de mayo de 1974 llamó a los Montoneros "imberbes y estúpidos" y los echa de la Plaza de Mayo; un poco después el 1 de julio de 1974 murió Perón y ante esta situación se hizo cargo de la presidencia su esposa que era la vicepresidenta, quien debió enfrentar el problema sumamente difícil por el que atravesaba el país. La crisis petrolera de 1973 repercutió en la Argentina por el incremento de los precios de los bienes importados. Las reservas se estaban agotando y la balanza de pagos registró un enorme déficit. Isabel Perón se vio ante la disyuntiva de subir los salarios como lo solicitaba la clase trabajadora u optar por combatir la inflación. Inmersa en esta situación que se agrava en 1975 porque las organizaciones guerrilleras se hacían sentir con mayor fuerza, se produjo una lucha abierta entre los militares y los guerrilleros. El Ejército Revolucionario del Pueblo (ERP) estaba logrando el control de la Provincia de Tucumán. Todo esto produjo el ingreso y funcionamiento de todo el aparato militar y policial del país que llevó a una violencia represiva de gran envergadura.

\section{EL PROCESO DE "REORGANIZACIÓN NACIONAL"}

El 24 de marzo de 1976 se produjo el golpe de estado, por la Junta Militar, conformada por los Comandantes en Jefes: General Jorge Rafael Videla, Almirante Emilio Eduardo Massera y Brigadier General Orlando Ramón Agosti, quienes presentaron al país los documentos institucionales básicos que habían preparado : la Proclama, el Acta con el propósito y los objetivos básicos del llamado Proceso de Reorganización Nacional, las bases para la intervención de las Fuerzas Armadas en dicho Proceso y el Estatuto. Los cinco documentos serian identificados como leyes fundamentales, y el régimen militar como el Proceso.

Los objetivos señalados en el Acta buscaban "una soberanía politica basada en el accionar de instituciones revitalizadas", "vigencia de los valores de la moral cristiana, de la tradición nacional y de la dignidad de ser argentino". Este régimen militar se instaló en 1976 hasta 1983 y se tuvo que retirar después que perdió en la Guerra de las Islas Malvinas de 1982, el ultimo de sus actos bochornosos. Produjo la derrota con trágico resultado.

Isabel Perón fue depuesta y arrestada por los militares, que establecieron una dictadura y fue esta la forma de gobierno que instituyeron 
y la que les permitió lo que buscaba, una profunda transformación en la economía, en la sociedad y en la política aplicando la más cruel de las represiones ante las protestas de la sociedad.

Se estableció el Estado de terror, se produjo la desaparición de miles de personas, el desmantelamiento de los sindicatos, la proscripción de los partidos políticos, la censura en los medios de comunicación y en toda expresión cultural, y a todo esto hay que agregar la existencia de campos de concentración y de exterminio de todos aquellos que se oponían a este proceso y fue durante este proceso que se conformaron los grupos económicos que obtuvieron grandes ganancias bajo la tutela de José Martínez de Hoz, Ministro de Economía nombrado por la Junta Militar. El Proyecto Económico-social de este ministro logró, según informan Azpiazu y Nochteff, que el producto bruto interno por habitante decreciera; la tasa de inversión cayó, la productividad de la sociedad argentina disminuyó, la economía se fue atrasando, no se modernizó y también se produjo el atraso tecnológico. Los salarios comenzaron a caer y aumentó la desocupación y la subocupación. Desde 1976 la participación de los trabajadores en la riqueza del país cayó del 49\% al 31\%, en beneficio de los sectores de mayor poder. Desde 1976 la pobreza aumentó. En 1974 el porcentaje de los hogares que no llegaban a comprar la canasta mínima necesaria para la subsistencia era del 4\%; los siguientes años se elevó llegando casi al 15\%.

A todos estos hechos se sumó el fin a las negociaciones colectivas de trabajo y se prohibieron las huelgas, por otro lado se dictaron medidas de carácter financiero que lograron liberar las tasas de interés, crear nuevos bancos e instituciones financieras que diversificaron y aumentaron las ofertas especulativas. El estado garantizó a los ahorristas la devolución del dinero si los bancos quebraban. Se aplicó una política económica liberal, y eliminó las leyes proteccionistas, lo que afectó la industria nacional que no pudo enfrentar la competencia de los productos extranjeros. Fue en esta época que una gran afluencia de dinero del exterior fue colocado sin riesgos, aprovechando las altas tasas de interés y las garantías que ofrecía el estado, estos fueron los capitales llamados "golondrinas", que se colocaban a corto plazo, los intereses que recibían eran altos y podían salir del país sin inconvenientes. La especulación se impuso sobre la inversión productiva, ninguna otra actividad podía competir con la especulación. Fue la época de la denominada "plata dulce".

A partir de 1980 la crisis estalló, las empresas tuvieron problemas, aumentaron las quiebras, los bancos y las financieras acumularon créditos 
incobrables, quebraron grandes bancos privados, el peso fue devaluado en un 400\% y la inflación llegó al 100\%. El Estado se hizo cargo, en 1982 de las deudas de los bancos y nacionalizó la deuda privada de las empresas, todo esto a partir de las decisiones tomadas por el ministro de economía Domingo Cavallo. Como resultado de estas medidas aumentó la deuda pública y privada del país, la deuda externa se hizo eterna, se produjo una concentración del poder económico y del poder de decisión en unos 30 grupos económicos y 100 empresas trasnacionales.

Otras de las características del periodo del "proceso" es que se hizo un uso discriminatorio de la ley que produjo un proceso de deslegalización de la vida social, todo lo cual se realizó en nombre de la "Doctrina de Seguridad Nacional", que se inspiró en el ejemplo de la lucha antirrevolucionaria y antisubversiva aplicada por Francia en Argelia y por Norteamérica en Vietnam. Esta doctrina consideró que el terrorismo y el comunismo eran los grandes enemigos de una sociedad ordenada, por esta razón el ejército debió ser capacitado para hacerle frente a este cáncer de la sociedad y la sociedad estaba obligada a prestar ayuda a las fuerzas armadas. De otro lado en la Escuela de las Américas, creada en 1946 en Panamá, obra del gobierno norteamericano, se formó a los militares y policías latinoamericanos en la conciencia anticomunista, fue allí donde se enseñaron las técnicas de interrogatorio y de tortura, así como también la manipulación de las masas (Triquier, 1963, p.63).

A partir de esta doctrina se justifica la tortura, el crimen y la desaparición, considerando que la aplicación de este método aportaba grandes ventajas como:

- Evitar la reacción internacional que suponen los fusilamientos masivos.

- Evitar la reacción del pueblo que no está preparado para la aplicación de la pena de muerte.

- El secuestro da grandes ventajas sobre el enemigo, porque se ignora si el secuestrado está vivo o muerto, permite la tortura sin límite de los detenidos.

- Evitar que luego del interrogatorio el detenido haga saber a sus compañeros la información que le fue arrancada.

- Facilita la aplicación masiva de la muerte de mujeres, ancianos, menores de edad y de figuras conocidas públicamente.

- Amparar el error y no permite acciones de víctimas inocentes

- Diluir las responsabilidades con vista al futuro (Duhalde, 1983, p.146-147). 
La política cultural aplicada por la dictadura fue poner en vigencia la censura a todas las actividades artísticas y científicas, imponiendo sobre todo la sospecha y:

- Se prohibió el uso de la minifalda

- Se prohibió usar barba y pelo largo

- Se prohibió usar jeans en las escuelas

- Se puso especial cuidado en desterrar del lenguaje términos que el proceso identificaba como sospechosos o peligrosos: por ejemplo eran vocablos peligrosos; burguesía, proletariado, cambio de estructuras, ecumenismo, liberación y compromiso, también se prohibió los trabajos de dinámica grupales, porque el "trabajo grupal”, según los miembros del Proceso había sustituido a la "responsabilidad personal". Y se proponía a los padres de los jóvenes que debían vigilar y denunciar todo aquello que estimase inconveniente para la formación del joven.

En la provincia de Córdoba, en noviembre de 1978, se prohibió la enseñanza de la matemática moderna, tanto en los colegios como en la universidad porque la consideraban enigmática, y como negaba los postulados de la lógica formal, era considerada útil para los subversivos.

En el diario La Nación del 31 de diciembre de 1978 existe un reportaje a Ernesto Sábato para preguntarle que pensaba de la palabra vector, porque había sido cuestionada por un funcionario de la provincia de Córdoba. Sábato respondió "que sí se censuraba ese vocablo habría que censurar la fisica entera, porque toda fuerza se representa con un vector; a menos que se haga una física sin fuerza, en cuyo caso habría que suprimir no sólo los tractores agrícolas sino también los tanques y aviones de guerra...".

Las políticas de la dictadura estuvo orientada por la sospecha respecto a la cultura, rechazando a los intelectuales y a la cultura letrada.

Quizás el mejor ejemplo de la mentalidad de los miembros de la Junta Militar se descubra en la declaración que dio, al diario La Opinión, el 26 de noviembre de 1977 el Almirante Massera que dijo: "La crisis actual de la humanidad se debe a tres hombres. Hacia fines del siglo XIX, Marx publicó tres tomos de El Capital y puso en duda con ellos la intangibilidad de la propiedad privada; a principios del siglo XX, es atacada la sagrada esfera íntima del ser humano por Freud, en su libro La interpretación de los sueños, 
y como si fuera poco para problematizar el sistema de los valores positivos de la sociedad, Einstein, en 1905 hace reconocer la teoría de la relatividad, donde pone en crisis la estructura estática y muerta de la materia"

La exclusión fue la nota preponderante ya sea material o simbólica de los autores y obras no aceptadas por este régimen. Se condenó al exilio a mucho de los disidentes. Otra modalidad de control de la cultura la constituyeron las "listas negras": que comprendían a los actores, periodistas, todo tipo de intelectuales que eran considerados "disolventes" y cuya aparición en los medios de comunicación estaba prohibida. También se establecieron "listas negras" de obras "no aconsejables" o "inmorales" y el mismo tratamiento se les dio a las películas. Como ya se ha mencionado eran disciplinas sospechosas: el psicoanálisis, el marxismo, la historia, la política y la matemática moderna.

Las obras censuradas fueran secuestradas y/o quemadas, esto produjo por parte de la población el terror de que se encontraran en sus casas ejemplares censurados, por lo cual se procedió a quemas individuales o a abandonar los libros en medio de terrenos baldíos, fue así como muchas bibliotecas, colectivas o individuales, perdieron innumerables ejemplares.

Luciano Benjamín Menéndez, jefe del III Cuerpo de Ejército, con asiento en Córdoba, ordenó una quema colectiva de libros el 29 de abril de 1976, entre los que se incluían obras de Proust, García Márquez, Cortázar, Pablo Neruda, Varga Llosa, Saint-Exupéry, Eduardo Galeano, entre muchos otros, con el argumento de "constituir un veneno para el alma de la nacionalidad Argentina".

Hobsbawn dijo que durante el periodo de entre guerra se implementó la tortura por parte de los regímenes comunista, fascista y nazi, y que de ahí en adelante se extendió por todo el mundo. En la guerra de Corea se usó la manipulación mental llamada "lavado de cerebro" y durante la lucha por la independencia de Argelia los franceses utilizaron de manera sistemática la tortura, hoy son muchos los gobiernos que recurren al uso de las armas químicas y biológicas; la Argentina cuenta en su haber el invento de la picana que, en un principio se aplicó para el ganado y que a partir del año 1930 se usó en los seres humanos.

Quien caía prisionero durante el Proceso, sentía la presencia de la muerte porque se lo aislaba lo que producía una ruptura con el mundo 
exterior, estaba encapuchado y sufría la pérdida de la visión, también perdía la noción del tiempo debido a la falta de movimiento y por último sufría la perdida de la autoestima.

Más allá de los documentos escritos está la memoria colectiva que se alimenta de fuentes orales, de ritos, monumentos y lugares que sintetizan y simbolizan acontecimientos y experiencias que forman parte de la identidad de un pueblo. La Plaza de Mayo en Buenos Aires es un ejemplo de memoria colectiva, en ella se vivieron grandes acontecimientos de la historia del pueblo argentino, desde 1810 en que fue lugar de reunión de los patricios frente al Cabildo, donde aguardaron con inquietud las noticias de la formación del primer gobierno patrio el 25 de mayo de 1810. En el siglo XX otro gran acontecimiento fue el 17 de octubre de 1945, allí los obreros se reunieron para pedir la libertad de Perón y por ultimo durante el Proceso se convirtió en el gran escenario donde las madres y abuelas de los desaparecidos se reunían una vez a la semana para hacer sentir su clamor pidiendo que les devolvieran a sus hijos y nietos; esas mujeres fueron capaces de enfrentarse a la más terrible de las dictaduras y de hacer oír su voz a nivel mundial.

La Organización de Madres de Plaza de Mayo comenzó a reunirse desde 1977. Ellas mismas relatan sus inicios: "Después de encontrarnos, desde marzo de 1976, en todos los comandos militares, en el Ministerio del Interior, en todas la Comisarias, en las cárceles, en todo lugar donde se podía preguntar por los hijos, y a casi un año de deambular por todas partes...decidimos hacer una presentación al ministro...volvíamos cada semana por novedades, a reclamar...hasta que un día la policía nos dijo que no podíamos estar reunidas porque había Estado de Sitio y que debíamos caminar. Ellos nos impulsaron a caminar...circulen, y nos tomamos del brazo y empezamos a caminar...llegábamos a la Plaza y nos poníamos en marcha para que la policía no nos corriera" (Revista Paz y Justicia, enero 1983).

Las Abuelas de Plaza de Mayo se constituyó en octubre de 1977 buscando a los niños desaparecidos (nacidos en cautiverio o secuestrados juntos con sus padres) para que se los devolvieran a sus legítimas familias.

El Informe de la Comisión Nacional sobre la Desaparición de Personas (CONADEP) presidida por Ernesto Sábato llegó a la conclusión que todo lo procedido por la Junta Militar llevó a la muerte de mucho de los presos como producto de la tortura, del fusilamiento colectivo, individual o 
por el lanzamiento al mar de gran número de personas y terminó señalando que todo esto fue producto de la "ejecución de una fría decisión".

En el informe de la CONADEP, documento que se conoce y fue publicado con el nombre de "Nunca más", Ernesto Sábato en el prólogo dice:

"Con tristeza, con dolor, hemos cumplido la misión que nos encomendó en su momento el Presidente Constitucional de la República. Esa labor fue muy ardua, porque debimos recomponer un tenebroso rompecabezas, después de muchos años de producidos los hechos, cuando se han borrado deliberadamente todos los rastros, se ha quemado toda documentación y hasta se han demolido edificios...Las grandes calamidades son siempre aleccionadoras, y sin duda el más terrible drama que en toda su historia sufrió la Nación durante el periodo que duró la Dictadura Militar iniciada en marzo de 1976 servirá para hacernos comprender que únicamente la democracia es capaz de preservar a un pueblo de semejante horror, que sólo ella puede mantener y salvar los sagrados y esenciales derechos de la criatura humana. Únicamente así podremos estar seguros de que nunca más en nuestra patria se repetirán hechos que nos han hecho trágicamente famosos en el mundo civilizado".

\section{REFERENCIAS BIBLIOGRÁFICAS}

DUSSEL, Inés; Finocchio, Silvia; Gojman, Silvia

2012 Haciendo Memoria en el País de Nunca Más. 2da Edición. Buenos Aires: EUDEBA.

FRANCO, Marina; Lenin, Florencia compiladoras

2007 Historia Reciente. Perspectivas y desafios para un campo en construcción. Buenos Aires: PAIDOS.

CONADEP

1997 Nuca Más. 3ra Edición. Buenos Aires: EUDEBA.

MONTES DE OCA, Ignacio

2014 Historia de la Argentina Olvidada. Tomo II. De la Revolución Libertadora al Kirchnerismo (1955-2013). Buenos Aires: EDHASA.

PARADERO, Hugo

2007 ¿Cómo es un recuerdo? Buenos Aires: Libros del Zorzal. 